\title{
Role of soluble urokinase plasminogen activator receptor (suPAR) as prognosis markers of neonatal sepsis
}

\author{
Retno Nurhayati ${ }^{1}$, Tri Yudani Mardining Raras ${ }^{2}$, Lintang Kawurjan ${ }^{3}$ \\ 1Biomedical Science Master Study Program/Pediatric Specialist Study Program, Faculty of Medicine \\ University of Brawijaya/dr. Saiful Anwar Hospital, Indonesia \\ 2 Biochemistry Department, Faculty of Medicine University of Brawijaya, Indonesia. \\ 3Neonatology Department, Faculty of Medicine University of Brawijaya/dr. Saiful Anwar Hospital, Indonesia
}

\begin{abstract}
Biological marker suPAR was used in many pathological conditions, including infection. suPAR was correlated with the severity of sepsis. The purpose of this study to determine levels of suPAR infants with risk of infection as a prognostic indicator for sepsis. Groups of infants with the risk of infection $(n=43)$ were followed prospectively on days $0,3^{\text {rd }}$ and $7^{\text {th }}$ and observed for the incidence of sepsis compared to the control group $(n=10)$. suPAR was measured by ELISA and the course of infection measured by clinical criteria. Results suPAR day 0, 3 and 7, displayed in the form of bloxpot and AUC as prognostic power. suPAR control levels $9.32 \mathrm{ng} / \mathrm{mL}$, sepsis cutoff 15, $41 \mathrm{ng} / \mathrm{mL}$ and AUC of 80.3\% [95\% CI 65.7\%, 94.9\%, $p=0.00$ ]. Graph shows ROC AUC sepsis suPAR day 0, the 3rd and 7th respectively 61.9\%, 66.6\% and 94.4\%. Sepsis with improved output $16.53 \mathrm{ng} / \mathrm{mL}$ and worsening $22.19 \mathrm{ng} / \mathrm{mL}$ and AUC of 80.8\% [95\% CI (0.62 to 0.99), $p=$ 0.02]. sUPAR levels was increased in neonatal sepsis patients. sUPAR could be used as a prognostic factor for neonatal sepsis.
\end{abstract}

Keywords -Urokinase plasminogen activator receptor, Neonatal sepsis.

\section{INTRODUCTION}

In a WHO report which quoted from State of the World's mother (2007) stated that $36 \%$ of neonatal deaths due to infectious diseases, including: sepsis; pneumonia; tetanus, and diarrhea $(1,2)$. Dr.. Saiful Anwar Malang Hospital suggests that neonatal sepsis incidence in 2009 was $4.8 \%$ with a mortality rate of $57.3 \%$ due to neonatal sepsis (3). Systemic Inflammatory Response Syndrome (SIRS) is a term commonly used for the identification of infection, although infection is not always found in patients with SIRS. This is a constraint to enforce sepsis in a timely manner. Examination of microbiological culture and antibiotic sensitivity as the gold standard sepsis could not give quick results, a minimum of 48 hours of sample inspection. This is a major problem in the process of establishing the diagnosis of early-onset neonatal sepsis, so that a given therapy based solely on risk factors and clinical signs. As a result, treatment of excessive and improper use of antibiotics will have an impact resistance of bacteriae (4).

Several biological markers have been used proven sepsis who have a fairly good diagnostic value but has limited prognostic value, especially to predict the output in accordance with the degree of severity of the disease. Biological markers that have been widely used as an evaluation of the CRP and PCT sepsis $(4,5)$. Both have a pretty good diagnostic value but still have limitations for predicting output sepsis. Urokinase plasminogen activator receptor (uPAR, CD87) is a plasminogen activation system components and receptor serine protease which is expressed by several immune cells such as neutrophils, eosinophils, monocytes and macrophages. Urokinase plasminogen activator receptor (UPAR) can cleave through a number of cell surface proteases such as chymotripsin, phospolipase $\mathrm{C}$ and UPA and produce a soluble form SuPAR has intrinsic properties of chemotaxis. SuPAR role against inflammatory processes in several processes including recruitment and migration of leucocytes. Physiological responses that occur at the beginning of inflammation, leukocytes in circulation will release chemotactic factors that cause some of them to work simultaneously process marginasi, adhesion, migration and chemotaxis (6). SuPAR as research on biological markers have been studied, including the malignant disease and some infections and inflammatory diseases including TB, HIV, pneumonia, sepsis, malaria, CNS infections and arthritis. SuPAR levels are also shown to be associated with the severity of SIRS and patients with bacteremia $(7,8)$

On condition of adult patients with bacteremia SuPAR obtained cutoff levels $11 \mathrm{ng} / \mathrm{mL}$ as a predictor of the severity of sepsis who have a sensitivity and specificity of $83 \%$ and $76 \%$ of the output. Other studies have also proved SuPAR as a predictor of mortality in intensive care patients and as an early marker of patients with organ failure (9) SuPAR of several studies in patients with bacteremia and sepsis performed with adult populations. While the study was the use of SuPAR as biological markers of sepsis in infants that we get the population is still limited, both as a diagnostic and prognostic. Therefore, the researchers plan to determine 
levels of serum SuPAR risk of infection in infants with neonatal sepsis on the output as an indicator of sepsis prognosis.

\section{METHODE}

This study was an cohort prospective. Groups of aterm infants with the risk of infection $(n=43)$ followed prospectively on days $0,3^{\text {th }}$ and $7^{\text {th }}$ and the observed incidence of sepsis compared to the control group $(\mathrm{n}=10)$. The study was conducted at the Perinatology Saiful Anwar Hospital and Faculty of Biomedical Laboratory Medicine, University of Brawijaya Malang. The research was carried out within 3 months from November 2012 to February 2013 that meet the inclusion and exclusion criteria.

Inclusion criteria for this study sample include term infants with neonatal infection appropriate risk criteria foul-smelling amniotic fluid, mother fever, asphyxia (1-minute Apgar score <6), prolonged labor, vaginal examination was not clean and premature rupture of membranes. Sample has not received antibiotic therapy before. Families allow their babies patients included in the study after being briefed (informed consent). Inclusion criteria for control group include term infants with no risk factors for infection. Healthy babies who have an indication for investigation such as babies with low birth weight (LBW), small gestational age (SGA) / IUGR, mothers with a history of hypertension / pre-eclampsia and diabetes mellitus, twin babies and baby makrosomia. Families allow patients included in the study after being briefed (informed consent) before.

Eclusion criteria for this study sample include infants who have congenital abnormalities. Term infants who did not meet the criteria of the risk of infection, there is no foul-smelling amniotic fluid, maternal fever is not, is not obtained asphyxia (1-minute Apgar score <6), did not experience prolonged labor, vaginal examination is clean, there is no history of premature rupture. Infants who have received blood transfusions prior to treatment. Infants with blood group incompatibility. Infants with severe sepsis (organ system disorders) at the beginning of treatment.

Infants with neonatal infection risk are infants who meet the criteria Gupte, 2003: Foul-smelling amniotic fluid, maternal fever, asphyxia (1-minute Apgar score <6), prolonged labor, vaginal examination was not clean and premature rupture of membranes. nfant and maternal risk factors merupakaan dominant factor to determine the occurrence of sepsis screening neonatorum. Skoring $\geq 5$ is an indication of antibiotic therapy. (table 1)

Table 1. Scoring system of neonatal sepsis risk factors

\begin{tabular}{lc}
\hline \multicolumn{1}{c}{ Criteria } & Score \\
\hline 1. Preterm & 3 \\
2. Foul smelling amniotic fluid & 2 \\
3. Maternal fever & 2 \\
4. Asphyxia (1-minute Apgar score <6), & 2 \\
5. Prolonged labor & 1 \\
6. Vaginal examination was not clean & 2 \\
7. Premature rupture of membranes & 1 \\
\hline
\end{tabular}

suPAR examination conducted 3 times while making the initial day 0 baby with the risk of infection (suPAR1), on the $3^{\text {rd }}$ day of treatment (suPAR 2) and day $7^{\text {th }}$ of treatment or earlier if there has been a disruption organ systems (suPAR 3). Whereas in the control infants examined once SuPAR levels, to determine baseline of SuPAR in healthy infants. suPAR examined by ELISA according to the protocol suPARnostic ViroGates A / S, Copenhagen, Denmark. Readings preparations Biotechmicro spectrum plate reader with $650 \mathrm{~nm}-450 \mathrm{~nm}$. CRP Levels examinations performed 3 times while making the initial day 0 babies born with the risk of infection (CRP 1), on the $3^{\text {rd }}$ day of treatment (CRP 2) and day $7^{\text {th }}$ of treatment or earlier if there has been a disruption organ systems (CRP 3). Whereas in the control infants examined CRP levels once, to determine baseline levels of CRP in healthy infants. CRP levels checked by immuno-turbidimetry method. Exodus sepsis can be divided into two, namely improvement and worsening. Improvement if the $7^{\text {th }}$ day there is a change in the direction of improvement in clinical symptoms and laboratory and found no sign of organ system disorders. Babies can be sent or taken care through polyclinics. Worsening if on day $7^{\text {th }}$ or earlier samples with severe sepsis continues to be marked organ dysfunction or death. Severe sepsis: sepsis with organ dysfunction cardiovascular / acute respiratory disorder / the 2 other organ disorders (neurological disorders, hematological, urogenital and hepatology). Blood culture tubes used BD BACTEC, Becton-made, Dickinson and Company. Taken before the administration of antibiotics. Result: positive and negative according to the type of bacteria that grow in culture media.

Data analysis is done by examined the completeness of data then grouping and tabulation in the data collection sheet. In this study, data analysis techniques will be performed five stages of counting, respectively: (1) test the normality of the data sample with Kolmogorov-Smirnov test, (2). When the normality test showed normal distribution of data, carried out between suPAR different test using the $t$ test, (3) to find out correlation between variables, we used Spearman test paired sample t test for pretest-posttest sample data, (4) ROC curve analysis was conducted to determine whether the levels of SuPAR has areas that are strong enough to determine 
the positive predictive value of neonatal sepsis incidence to the output (5) All calculations performed with the software of SPSS for Windows 15.0.

\section{Results}

The study included 43 patients $(n=43)$ infants with neonatal infection risk and 10 patients $(n=10)$ with healthy infants as controls who had inkulusi and exclusion criteria. Characteristics of neonatal infection risk and control based on several parameters related to the history of delivery, infants and some risk factors from mother. The whole is a term infants with an average age of 38 weeks and have average birth weight of 3140.7 grams. Infants born spontaneously as $n=21(48.8 \%)$, cesarean $n=21(48.8 \%)$ and by vacuum extraction $n=1$ (2.3\%). Distribution neonatal infection who had a risk of sepsis $\mathrm{n}=21(48.8 \%)$ and who did not have sepsis $\mathrm{n}=$ $22(51.2 \%)$. Infants with EOS $n=16(69.8 \%)$ and the LOS $n=7(30.2 \%)$. (Table 2)

Table 2. Baseline characteristics of sample

\begin{tabular}{|c|c|c|c|c|}
\hline \multirow{2}{*}{$\begin{array}{ll} & \text { Group } \\
\text { Characteristic } & \end{array}$} & \multicolumn{2}{|c|}{ Patients } & \multicolumn{2}{|c|}{ Control } \\
\hline & $\mathrm{n} / \mathrm{x}$ & $\% / \mathrm{SD}$ & $\mathrm{n} / \mathrm{x}$ & $\% / \mathrm{SD}$ \\
\hline \multicolumn{5}{|l|}{ Sex } \\
\hline Boy & 29 & $(67.4 \%)$ & 7 & $(70 \%)$ \\
\hline - $\quad$ Girl & 14 & $(32.6 \%)$ & 3 & $(30 \%)$ \\
\hline Gestational age (weeks) & 38.5 & $(\mathrm{SD}=1.2)$ & 37.8 & $(\mathrm{SD}=1.3)$ \\
\hline Birth weight & 3140.7 & $(\mathrm{SD}=490.1)$ & 2909.0 & $(\mathrm{SD}=325.3)$ \\
\hline \multicolumn{5}{|l|}{ Diagnosis } \\
\hline Sepsis & 21 & $(53.5 \%)$ & 0 & $(0 \%)$ \\
\hline non sepsis & 22 & $(46.5 \%)$ & 10 & $(100 \%)$ \\
\hline \multicolumn{5}{|l|}{ Chorioamnionitis } \\
\hline no & 24 & $(55.8 \%)$ & 0 & $(0 \%)$ \\
\hline Yes & 19 & $(44.2 \%)$ & 10 & $(100 \%)$ \\
\hline \multicolumn{5}{|l|}{ Maternal temperature } \\
\hline Normal & 26 & $(60.5 \%)$ & 10 & $(100 \%)$ \\
\hline Fever & 17 & $(39.5 \%)$ & 0 & $(0 \%)$ \\
\hline \multicolumn{5}{|l|}{ Asphyxia } \\
\hline - Yes & 31 & $(72.1 \%)$ & 0 & $(0 \%)$ \\
\hline No & 12 & $(27.9 \%)$ & 10 & $(100 \%)$ \\
\hline \multicolumn{5}{|l|}{ PROM } \\
\hline - Yes & 21 & $(48.8 \%)$ & 0 & $(0 \%)$ \\
\hline No & 22 & $(51.2 \%)$ & 10 & $(100 \%)$ \\
\hline \multicolumn{5}{|l|}{ EOS } \\
\hline - $\quad$ Yes & 30 & $(69.8 \%)$ & 0 & $(0 \%)$ \\
\hline No & 13 & $(30.2 \%)$ & 10 & $(100 \%)$ \\
\hline \multicolumn{5}{|l|}{ LOS } \\
\hline Yes & 13 & $(30.2 \%)$ & 0 & $(0 \%)$ \\
\hline - $\quad$ No & 30 & $(69.8 \%)$ & 10 & $(100 \%)$ \\
\hline \multicolumn{5}{|l|}{ Delivery } \\
\hline Spontan & 21 & $(48.8 \%)$ & 5 & $(50 \%)$ \\
\hline Ceasar-section & 21 & $(48.8 \%)$ & 5 & $(50 \%)$ \\
\hline Vacuum extraction & 1 & $(2.3 \%)$ & 0 & $(0 \%)$ \\
\hline
\end{tabular}

One-way ANOVA test results were shown in Table2.There was no significant difference (p-value $>0,05)$ 
Table 3 The mean levels of CRP in day 0 (CRP 1), day 3 (CRP 2) and day 7 (CRP 3)

\begin{tabular}{|c|c|c|c|}
\hline \multirow[t]{3}{*}{ Measured } & \multicolumn{3}{|c|}{$\begin{array}{c}\text { Mean of CRP } \\
(\mathrm{mg} / \mathrm{L})\end{array}$} \\
\hline & \multicolumn{3}{|c|}{ Group (n) } \\
\hline & $\begin{array}{l}\text { Sepsis } \\
(21)\end{array}$ & $\begin{array}{c}\text { No sepsis } \\
\text { (22) }\end{array}$ & $\begin{array}{l}\text { Control } \\
\text { (10) }\end{array}$ \\
\hline CRP 1 & 5,357 & 2,851 & 0,832 \\
\hline CRP 2 & 2,312 & 2,474 & - \\
\hline CRP 3 & 3,124 & 2,874 & - \\
\hline
\end{tabular}

Table 4. The mean level of SuPAR in day 0 (suPAR 1), day 3 (suPAR 2) and day 7 (suPAR3)

\begin{tabular}{lccc}
\hline Measured & \multicolumn{3}{c}{$\begin{array}{c}\text { Mean of suPAR } \\
(\mathrm{ng} / \mathrm{mL})\end{array}$} \\
& \multicolumn{3}{c}{ Group (n) } \\
& Sepsis & No sepsis & Control 1 \\
& $(21)$ & $(22)$ & $(10)$ \\
\hline suPAR 1 & 14,918 & 13,259 & 9,721 \\
suPAR 2 & 18,186 & 17,181 & - \\
suPAR 3 & 26,931 & 12,604 & - \\
\hline
\end{tabular}

From normality test results, levels of CRP have a normal distribution with a significance value of 0.72 (p> $0,05)$. The results of the $t$ test showed a significance of $0.449(p<0,05)$. While the results of Levene's test (homogeneity test) showed that CRP levels among infants 3 sepsis and non-sepsis also has a significance value 0.299 ( $\mathrm{P}<0.05$ ), so the t-test results obtained with equal variances assumed, so it can be concluded that the CRP level 3 on infant sepsis and non-sepsis was not a significant difference (table 3 ).

Based on the test for normality, SuPAR levels have a normal distribution with a significance value of 0.213 ( $>$ > 0,05). While the results of the t test for comparison SuPAR 3 levels among infants with sepsis and nonsepsis indicate significance value 0.014 ( $\mathrm{p}<0.05)$, thus SuPAR 3 levels in infants sepsis and sepsis there were significant differences. Spearman correlation test looks at levels of 1 SuPAR, SuPAR 2 does not have a significant relationship with the incidence of sepsis. As with the SuPAR 3 that have a significant correlation with the incidence of sepsis $(r=-0447)$ with a significance value $(p=0.003<0.05)$, so it can be concluded that there is a significant relationship between SuPAR with sepsis, with the closeness of the relationship that quite strong and significant negative correlation, meaning that the higher levels of SuPAR will be more at risk of developing sepsis, and vice versa (table 4).
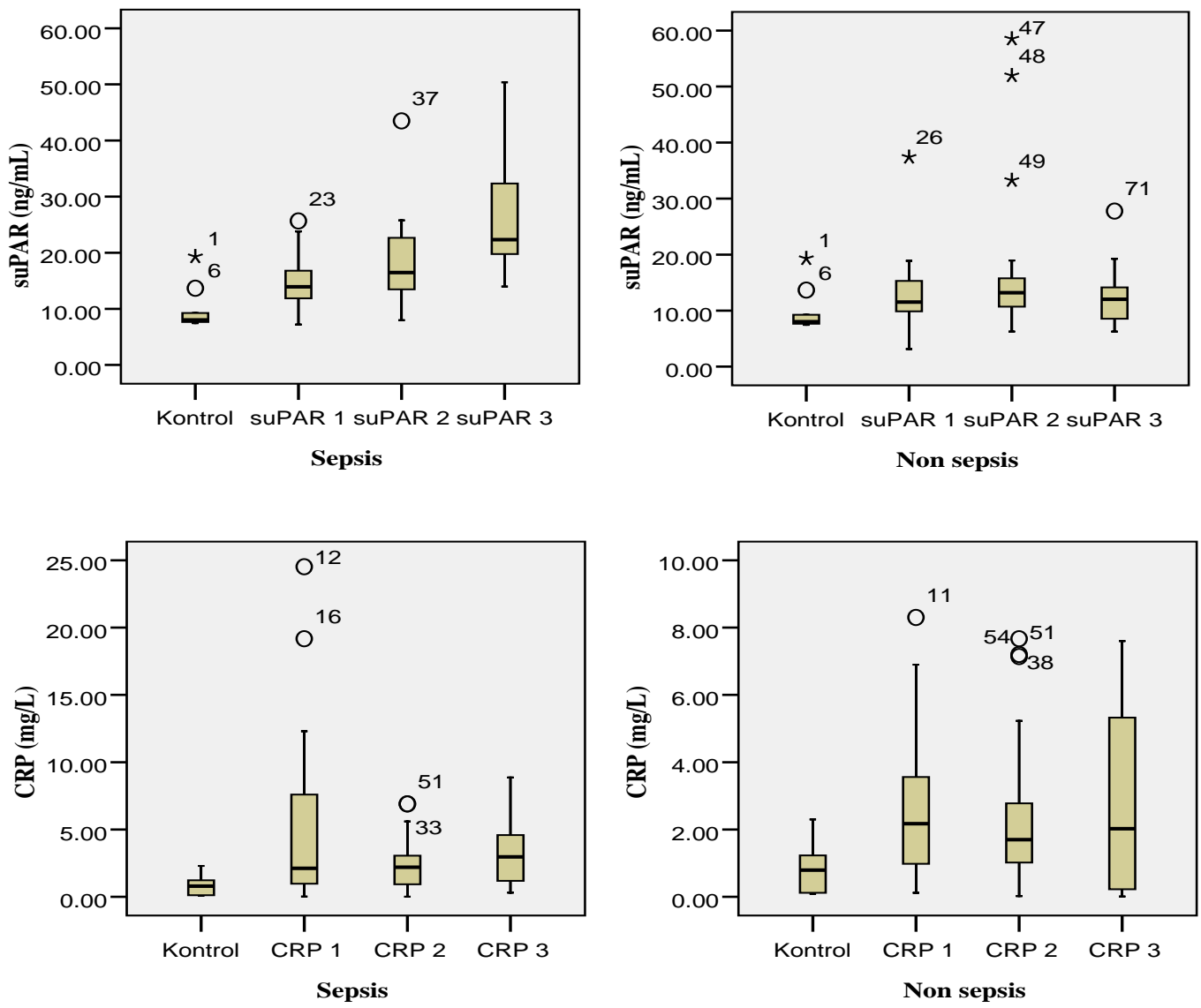

Figure 1 Bloxpot of CRP and suPAR infant sepsis and non sepsis in day $0,3^{\text {rd }}$ and $7^{\text {th }}$ 
Measurement of suPAR groups of neonatal infection risk who developed sepsis, non sepsis and control indicated an increase in septic infants compared with infants without sepsis on day observations $3^{\text {rd }}$ and the $7^{\text {th }}$. CRP levels in neonatal risk infection showed no corresponding increase in levels of observation time, a trend to decrease the mean levels of CRP in the observations to 2 and to 3 (figure 1).
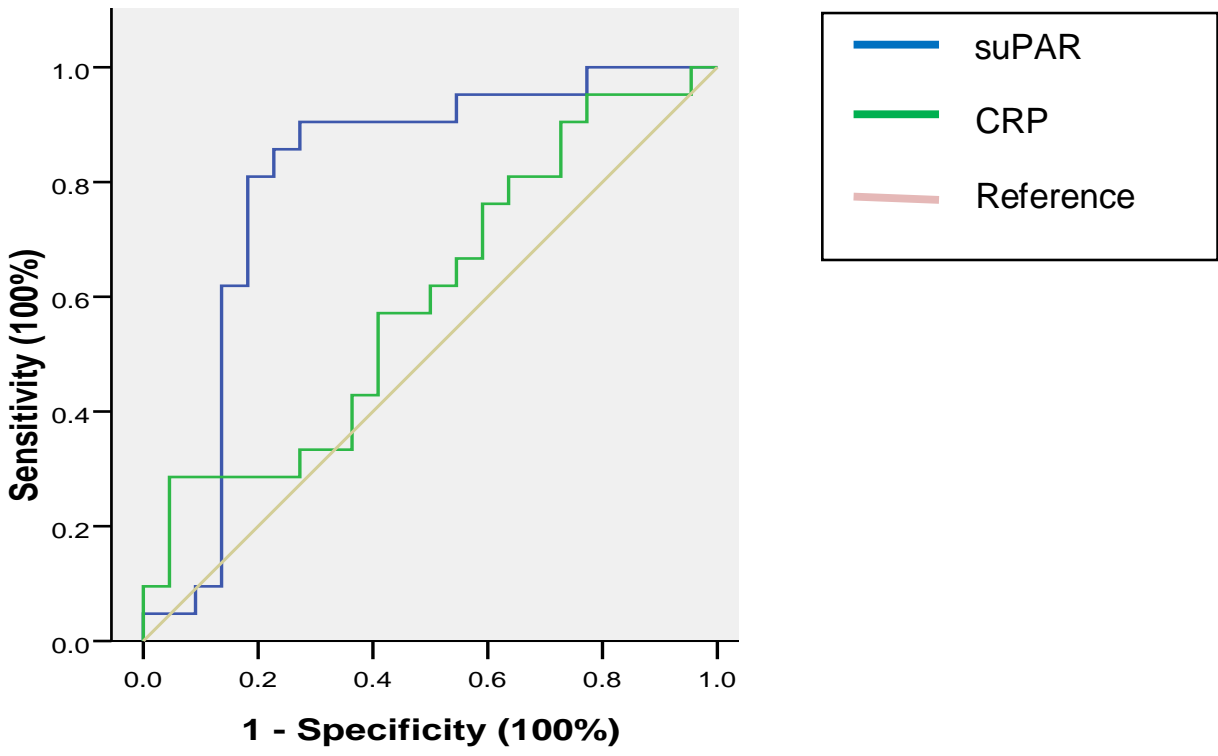

Figure 2. ROC / AUC between CRP levels and SuPAR

In this study the threshold biomarker CRP and SuPAR determined using analysis of Receiver Operating Curve (ROC). Levels of SuPAR looks more close to the line 100\%. AUC values obtained from ROC method amounted to $59.7 \%$ for CRP $(95 \%$ CI $42.6 \%-76.9 \%, \mathrm{p}=0.274)$ ) and $80.3 \%$ for SuPAR $(95 \%$ CI 65 , $7 \%-94.9 \%$, with $\mathrm{p}=0.001$ (figure 2 )

Table 5 Levels of CRP and SuPAR with the incidence of sepsis, based right threshold value (Cutoff)

\begin{tabular}{lll}
\hline SuPAR $(\mathbf{n g} / \mathbf{m L})$ & \multicolumn{1}{c}{$\begin{array}{c}\text { Non Sepsis } \\
(\mathbf{n} / \%)\end{array}$} & \multicolumn{1}{c}{$\begin{array}{c}\text { Sepsis } \\
(\mathbf{n} / \%)\end{array}$} \\
CRP $(\mathbf{m g} / \mathbf{L})$ & $18(41,9 \%)$ & $4(9,3 \%)$ \\
SuPAR $<15,41$ & $4(9,3 \%)$ & $17(39,5 \%)$ \\
SuPAR $\geq 15,41$ & $13(30,2 \%)$ & $9(20,9 \%)$ \\
CRP $<3,06$ & $9(20,9 \%)$ & $12(27,9 \%)$ \\
CRP $\geq 3,06$ & & \\
\hline
\end{tabular}

ROC analysis also produce the sensitivity and 1-specificity at various threshold values (cutoff). In this study both biomarkers serve as diagnostic and prognostic tools that set the threshold value $15.41 \mathrm{ng} / \mathrm{mL}$ for SuPAR levels and $3.06 \mathrm{mg} / \mathrm{L}$ for CRP levels (table 5).
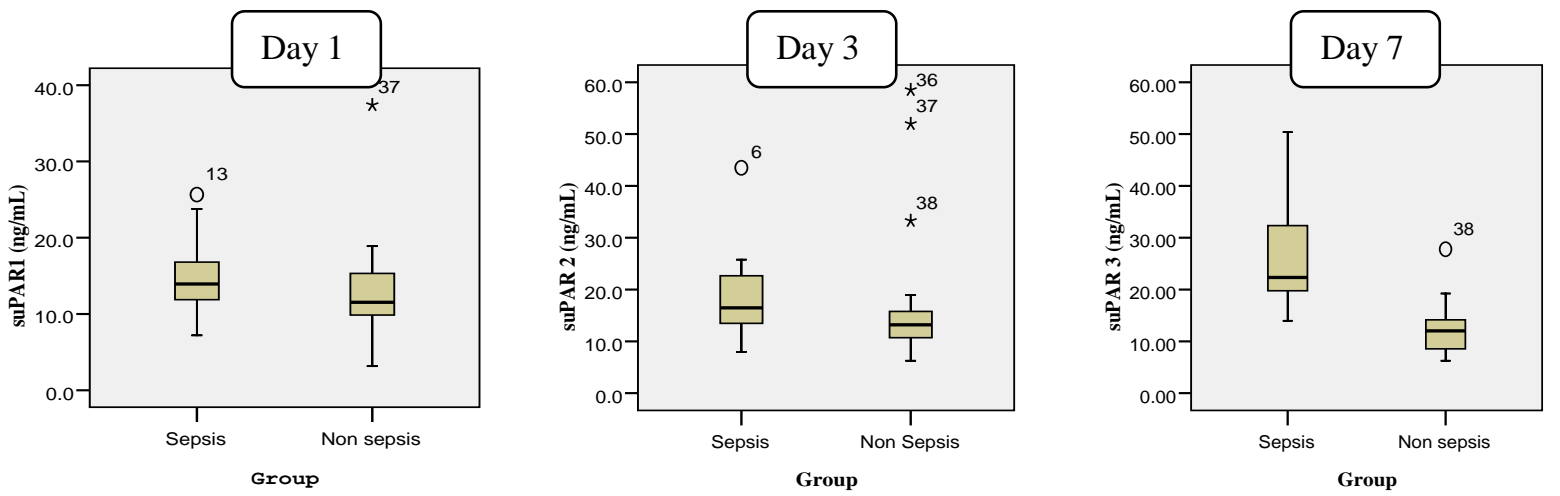

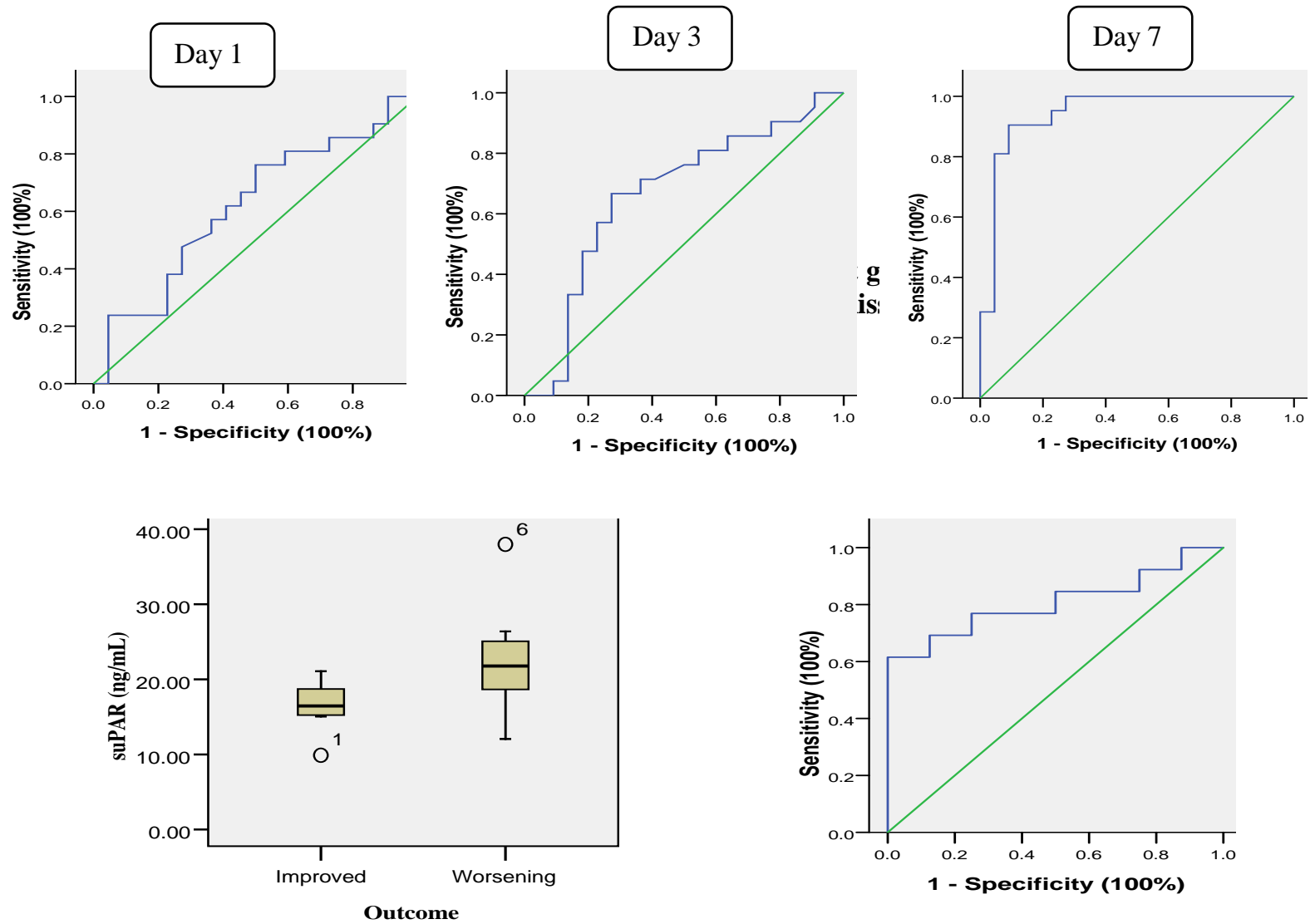

Figure 4. Prognostic power of rsuPAR in patients with sepsis. Boxplot graphic and ROC curve analyses showing the prognostic power of suPAR for Outcome patients with neonatal sepsis

The mean SuPAR infants with neonatal sepsis is correlated with ROC graphs to prove the existence of a significant increase in a row SuPAR AUC values in infants with sepsis on day 0 (SuPAR 1), day $3^{\text {rd }}$ (SuPAR 2 ) and the $7^{\text {th }}$ (SuPAR 3) there were 61.9\%, 66.6\% and 94.4\% (figure 3). Thus obtained are also significant differences in infants with neonatal sepsis who have output improved and worsened on days $0,3^{\text {rd }}$ and $7^{\text {th }}$ days of treatment (figure 4). Obtained differences in mean levels of SuPAR sepsis have improved by $16,53 \mathrm{ng} / \mathrm{mL}$, while the worsened infants $22,19 \mathrm{ng} / \mathrm{mL}$. ROC AUC value on the graph $80,8 \%$, CI $95 \%$ (0.62 to 0.99$)$ and $\mathrm{p}=$ 0,02 (Figure 4).

The dominance of infant sepsis blood culture results showed $38.1 \%$ sterile. While most bacteria Klebsiella pneumonia consecutive $19 \%$ and $14.3 \%$ Serratia liquefacients (table 6).

Table 6. Distribution of types of bacteriae from blood cultures in infants with sepsis

\begin{tabular}{ll}
\hline \multicolumn{1}{c}{ Bacteriae } & \multicolumn{1}{c}{$n$ /Persentage(\%) } \\
\hline Acinetobacter wofii & $1(4,8)$ \\
E. coli & $1(4,8)$ \\
Enterobacter gergoviae & $1(4,8)$ \\
Klebsiella pneumonia & $4(19)$ \\
Serratia liquefacients & $3(14,3)$ \\
Staphylococcus coagulase negative & $3(14,3)$ \\
sterile & $8(38,1)$ \\
Total & $21100)$ \\
\hline
\end{tabular}

\section{Discussion}

The result showed the mean SuPAR in normal infants was $9.32 \mathrm{ng} / \mathrm{mL}$. Few studies SuPAR levels in the adult population has been studied. Some of them carried out by Koch, 2011 SuPAR average levels in the control of 2,44 $\mathrm{ng} / \mathrm{mL}$, by Noorchozin, 2011 has SuPAR was $4.77 \mathrm{ng} / \mathrm{mL}$ and by Setyarini (2012) found normal levels of children range from 1,58 SuPAR $\pm 0.64 \mathrm{ng} / \mathrm{mL}(10-12)$. Whereas in our study, Some things 
that can explained SuPAR levels in newborns is higher than that in children, the first since the newborn has a different physiology with children, where at the beginning of life gained due to an increased in hemoglobin concentration of plasma extravasation experience compensated for placental transfusion and increased in circulating erythrocyte volume that occurs shortly after birth, subsequent hemoglobin concentration will decreased gradually at the age of 8-12 weeks of age birth to $11,4 \pm 0,9 \mathrm{~g} / \mathrm{dl}$. Increasing in hemoglobin that occurs in infants is a physiological process (13). Normal suPAR values obtained infant higher than levels in normal conditions the child's age. This condition will affect the levels suPAR significant and technical methods, as written in the manual guide suPARnostic ${ }^{\circledR}$ kit reference hemoglobin levels that can affect levels ranged SuPAR $14,92 \mathrm{mg} / \mathrm{dl}$, while the mean hemoglobin levels are relatively normal infants than children and adults(14). The second cause SuPAR allowing normal levels in infants due to higher in infants aged 2 days starting obtained physiological hyperbilirubinemia. In the term infants who received breast milk, peak bilirubin levels will reach higher levels $(7-14 \mathrm{mg} / \mathrm{dL})$ and a decrease occurred more slowly. Increased to $10-12 \mathrm{mg} / \mathrm{dL}$ is still within the physiological range, even up to $15 \mathrm{mg} / \mathrm{dL}$ without accompanied bilirubin metabolism disorders (15). This condition will also affect the levels were significantly SuPAR. Mentioned that the reference levels of bilirubin which can affect SuPAR when bilirubin levels reached >9 mg / dL (16).

Similar to normal suPAR levels in normal infants, SuPAR on the clinical condition of infants with infection and sepsis was still in the research stage and there has been no publication of magnitude SuPAR of neonatal infection. In the adult acquired bacteremia threshold value (cutoff) was $9,25 \mathrm{ng} / \mathrm{mL}$, sensitivity $79 \%$ and specificity of $68 \%$ and AUC 0.75 (95\% CI) (17). While the condition of sepsis obtained cutoff $11 \mathrm{ng} / \mathrm{mL}$. In this study, the cutoff score is high enough for a neonatal infection with sepsis, which is equal to $15,41 \mathrm{ng} /$ $\mathrm{mL}$ with the AUC of $80,3 \%$ (95\% CI 65,7\% 94,9\%, with $\mathrm{p}=0,001$ ). On the condition of infants with severe infections or sepsis, suPAR higher than normal value. It caused by one in hypoxic conditions due to disruption of the cardiovascular system. Sepsis begins with the response to the systemic inflammatory process description, coagulopathy, impaired fibrinolysis which further raises circulation and perfusion disturbance that ended with organ disfunction (18). Due to decreased perfusion, the brain was an organ that is very important. One of the criteria for infants with neonatal infection risk was asphyxia. Asphyxia in infants have an impact on the occurrence of oxidative stress. It will continued to increase in erythrocyte hemolysis. Infants with severe sepsis who have septic shock will experience greater oxidative stress due to hypoxia involving multiple organ systems and metabolic acidosis. As a result of this ongoing process several inflammatory processes occurs so quickly such a rapid movement of neutrophils and monocyte adhesion and migration. This proccess will continude in accordance with the degree of severity of disease $(19,20)$

SuPAR in the blood circulation associated with clinical parameters of SIRS, bacteremia and sepsis. Although the research still limited in neonatal populations. Diagnosis of neonatal with the risk of infection limited based on anamnesis, physical examination and clinical parameters for early recognition of neonatal sepsis incidence. But sometimes the clinical parameters and scoring system were further from the process that occurs during intrauterine infection, so that enforcement is still difficult to predict neonatal sepsis. Beside that, it could not be used as a monitoring antibiotic therapy. Several investigations have been long time that is not used as a diagnostic tool of sepsis. Some investigations are based on biomarkers have been developed, including; haematological markers, acute phase proteins, complement system, chemokines, cytokines and adhesion molecules as well as several other biomarkers. In the research that has been conducted in inflammatory conditions, SuPAR showed that increased level of suPAR parallel with disease severity and mortality. Instead SuPAR levels will decline in patients who have received therapy and adequate treatment consistent with patients experiencing clinical improvement. It can be concluded that the strength SuPAR has predictive value for the degree course of the disease (8).

Our suPAR study prospectively measured 3 times at day 0 (SuPAR 1 ), day $3^{\text {rd }}$ (SuPAR 2 ) and day $7^{\text {th }}$ (SuPAR 3). Infants with neonatal sepsis incidence increased levels of early and late SuPAR significant ie $18.06 \%$ (table 2). While based on the relationship between suPAR and the incidence of neonatal sepsis SuPAR $r=-0.447$ and $p=0,003(\alpha<0,05)$, meaning that the higher levels of SuPAR increase the risk of neonatal sepsis. The increasing SuPAR were positively correlated with the inflammatory process associated with the involvement of the pathway SuPAR plasminogen activation system, inflammatory modulate of cell adhesion, migration and proliferation. In the event of clinical signs of SIRS, SuPAR formed by the release of proteolytic enzymes from cells (uPAR). SuPAR directly stimulated the chemotaxis of inflammatory cells such as neutrophils, macrophages, and phagocyt. UPAR released in the circulation process is not only due to inflammation, but more because of the inability of the host defense. This is the one that can explain SuPAR levels have prognostic value is quite high compared with other biomarkers (8).

In this study a comparison of the prognostic value of biomarkers that have been used there are used daily in clinical practice at the hospital. From the results of measurements of the mean value of 3 times (on days $0,3^{\text {rd }}$ and $7^{\text {th }}$ ), each measurement obtained an inverse relationship with the degree of severity of neonatal sepsis (CRP 1 was 5,35 mg / L, CRP 2 was 2,31 mg / L and CRP 3 was 3,12 mg/L) while the correlation of test 
results obtained levels of CRP1, CRP2 and CRP3 not have significant value to the incidence of sepsis, consecutively $0.774,0.952$ and 0.276 . It is known from the significant value of these three categories is more than alpha $(\alpha>0.05)$. Examination of CRP protein will increase in the acute phase and increased tissue damage in patients with sepsis. Increased CRP levels occurred after 24 hours after sepsis occurred. This examination could not be used as a single indicator in the diagnosis of sepsis. Determination of the CRP cutoff value has yet to have an agreement to determine the presence of infection. In the study conducted by Chelik (2010) obtained a cutoff of 4,28 mg / dl. This value is only performed at the beginning to establish the diagnosis of sepsis, but not CRP can be used to monitor neonatal sepsis, so CRP was only used as a marker for early diagnosis of sepsis (21). In this study obtained cutoff CRP value of $3,06 \mathrm{mg} / \mathrm{L}$ and not shown to be used as a prognostic marker in accordance with the severity of sepsis.

The gold standard for diagnosis of neonatal sepsis is blood culture. Positive culture results are obtained definite signs of sepsis causing pathogens. Weakness of culture examination in patients with suspected sepsis was still not produced satisfactory results, due to long examination, the results of which are not in accordance with the clinical and high cost (22). From the results of this study, a sterile culture in 8 infants with clinical sepsis $(38,1 \%)$. Most bacteria was Klebsiella pneumonia (19\%). Several explanations can account for the incidence of infant sepsis with sterile culture results based on the results of studies such as sepsis in infants obtained only about 2-25\% positive bacteria found in the blood. At Mhada research (2012) showed different results with our study, which is one of the most germ causes of infant sepsis group Klebsiella pneumonia by $22 \%$ (23). This is due among others to the risk of infection in infants associated with maternal or intrauterine infection, the mother will be given intravenous antibiotics during labor. Moreover cause sterile results in septic patients in these patients could be due to several methods, blood cultures performed only once (it was better done 2 times on different extremities and locations) (24). According to research Guerti (2011) stated sampling $<72$ hours will affect the incubation time cultured bacteria cultures in infants and be repeated after 72 hours (25). Bacteria culture results in this study also found some positive results indicate the possibility of bacteria are not in circulation, but because contamination during sampling results (26).

\section{Conclusions}

suPAR level in infants with neonatal infection risk is higher as compared to controls. suPAR average levels in infants with neonatal sepsis is higher compared with infants without neonatal sepsis. There is an increase in the average levels of suPAR in infants with neonatal sepsis who experience worsening. suPAR can to be an indicator of good prognosis compared with changes in CRP levels in infants at risk of infection. The need for similar studies with samples of urine or saliva of babies born with the risk of infection compared with suPAR serum.

\section{References}

[1] A. Aminullah, M. Gatot, Kosim S , R. Rohsiswatmo, F. Indarso, R. Dharma, penatalaksanaan sepsis neonatorum, Universitas indonesia, Jakarta, 2007.

[2] A. Deorari, S. Broor, R. Maitreyi, D. Agarwal, H. Kumar, V. Paul, M. Singh, Incidence, Clinical Spectrum, and Outcome of Intrauterine Infections in Neonates. Journal of Tropical Pediatrics, 46, 2000, 155-160.

[3] I. IRNA, Laporan tahunan instalasi rawat inap IV, Malang, dr. Saiful Anwar Hspital, 2009, 67-71.

[4] N. Pak, H. Lam, Diagnostic markers for neonatal sepsis. Current Opinion of Pediatrics, 18, $2006,12531$.

[5] K. Jessen, S. Lindboe, A. Petersen, J. Eugen-Olsen, T.B. T, Common TNF- $\alpha$, IL-1 $\beta$, PAI-1, uPA, CD14 and TLR4 polymorphisms are not associated with disease severity or outcome from Gram negative sepsis. BMC Infectious Disease, 7, 2007, 108-15.

[6] M. Jo, S. Thomas, L. Wu, S.G.S. L, Soluble Urokinase-type Plasminogen Activator Receptor Inhibits Cancer Cell Growth and Invasion by Direct Urokinase-independent Effects on Cell Signaling. Journal of Biological Chemistry, 278 (47), 2003, 46692-46698

[7] Y. Gürdal, S.I. Köksal, C Karahan, A. Mentese, The diagnostic and prognostic significance of soluble urokinase plasminogen activator receptor in systemic inflammatory response syndrome, Clinical Biochemistry, 44, 2011, 1227-1230

[8] Y. Backes, K. Sluijs, A. Boer, J. Hofstra, A. Vlaar, R. Determann, P. Knape, D. Mackie, M. Schultz, Soluble urokinase-type plasminogen activator receptor levels in patients with burn injuries and inhalation trauma requiring mechanical ventilation: an observational cohort study. Critical Care, 15 (R270), 2011, 2-11.

[9] J. Ville, Y. Runkuan, L. Rita, H. Heini, O. Marjatta, V. Tero, P. Ville, T. Jyrki, SuPAR and PAI-1 in critically ill, mechanically ventilated patients. Intensive Care Medicine, 39 (3), 2012, 489-496.

[10] A. Koch, S. Voigt, C. Kruschinski, E. Sanson, H. Duckers, Circulating soluble urokinase plasminogen activator receptor is stably elevated during the first week of treatment in the intensive care unit and predicts mortality in critically ill patients. Critical Care, 15 , 2011, 1-14.

[11] E. Setyarini, M. Kusuma, T. Raras, Perbedaan kadar soluble urokinase-type plasmonogen activator receptor (suPAR) di serum dan urin pada anak yang didiagnosis TB paru, postgraduate S2, brawijaya university, malang, 2012.

[12] I. Chozin, T. Raras, N. Muktiati, Studi prospektif: Kadar soluble urokinase plasminogen activator receptor (suPAR) selama terapi OAT pada penderita Tuberkulosis paru, post gradute, Brawijaya, Malang, 2009.

[13] V. Blanchette, Y. Door, A. Chan (Eds.), Avery's Neonatology pathophysiology and management of the newborn, Philadelphia, Lippincort william \& walkins, 2005.

[14] VIroGates, suPARnostic® : Enzyme immunoassay for quantitative determination of soluble urokinase plasminogen activator receptor in human plasma, Copenhagen, Denmark, 2008.

[15] S. Blackburn (Ed.) Maternal fetal \& neonatal physiology, a clinical perspective, Missouri, Saunders, 2007.

[16] Q. Huai, et al., Structure of human urokinase plasminogen activator in complex with its receptor. Science, 3 (311), 2006, 565-9. 
[17] K. Kofoed, O. Andersen, G. Kronborg, M. Tvede, J. Petersen, J. Eugen-Olsen, K. Larsen, Use of plasma C-reactive protein, procalcitonin, neutrophils, macrophage migration inhibitory factor, soluble urokinase-type plasminogen activator receptor, and soluble triggering receptor expressed on myeloid cells-1 in combination to diagnose infections: a prospective study. Critical Care, 11:R38, 2007.

[18] M. Short Linking the Sepsis Triad of Inflammation, Coagulation, and Suppressed Fibrinolysis to Infants. Adv Neonatal Care 5,2004, 258-73

[19] B. Dessau, J. Bongain, V. Molina, J. Quilodrá, R. Castillo, R.R. Bongain, V. Molina, J. Quilodrán, Oxidative stress as a novel target in pediatric sepsis management. Journal of Critical Care, 26, 2011, 103.e1-103.e7.

[20] S. Perrone, MLTataranno, G. Stazzoni, G. Buonocore, Oxidative stress and free radicals related diseases of the newborn. Advances in Bioscience and Biotechnology, 3, 2012, 1043-1050

[21] I. Celik, F. Demirel, N. Uras, S. Oguz, S. Erdeve, Z. Biyikli, U. Dilmen, What are the cut-off levels for IL-6 and CRP in neonatal sepsis? J.clin.lab. Anal, 24, 2010, 407-12.

[22] S. Tripathi, G. Malik, Neonatal Sepsis: past, present and future; a review article. Internet Journal of Medical, 5 (2), $2010,45-54$.

[23] T. Mhada, F. Fredrick, M. Matee, A. Massawe, Neonatal sepsis at Muhimbili National Hospital, Dar es Salaam, Tanzania; aetiology, antimicrobial sensitivity pattern and clinical outcome. BMC Public Health, 12, 2012, 904.

[24] F. Cockerill, J. Wilson, E. Vetter, K. Goodman, C. Torgerson, W. Harmsen, C. Schleck, Optimial testing parameters for blood culture. Clinical ibfectious disease, 38, 2004, 1734-30.

[25] K. Guerti, H. Devos, M. Leven, L. Mahieu, Time to positive of neonatal blood culture: fast and furious? , Journal of medical microbiology (60), 2011, 446-53.

[26] Z. Hashemizadeh, A. Bazaargani, M. Davarpanah, Blood Culture Contamination in a Neonatal Intensive Care Unit in Shiraz, Southwest-Central Iran Medical Principles and Pracyice, 20, 2011, 133-6. 